\title{
Surgical Resection for Crohn's and Cancer: A Comparison of Disease-Specific Risk Factors and Outcomes
}

\author{
David W. Larson ${ }^{a} \quad$ Mohamed A. Abd El Aziz ${ }^{a} \quad$ William Perry ${ }^{a} \quad K e v i n ~ T . ~ B e h m^{a}$ \\ Sherief Shawki $^{\mathrm{a}}$ Jay Mandrekar ${ }^{\mathrm{b}}$ Kellie L. Mathis ${ }^{\mathrm{a}}$ Fabian Grass ${ }^{\mathrm{c}}$

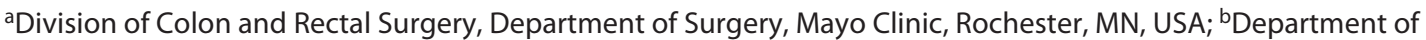 \\ Health Sciences Research, Mayo Clinic, Rochester, MN, USA; 'Department of Visceral Surgery, Lausanne University \\ Hospital CHUV, University of Lausanne, Lausanne, Switzerland
}

\section{Keywords}

Crohn's disease - Colon cancer $\cdot$ Right colectomy · Morbidity

\begin{abstract}
Background and Objectives: The goal of this study was to compare disease-specific risk factors and 30-day outcomes between patients with Crohn's disease (CD) and colon cancer (CC) undergoing right-sided surgical resection. Methods: The American College of Surgeons-National Surgical Quality Improvement Program (ACS-NSQIP ${ }^{\circ}$ ) was interrogated to extract all patients $\geq 18$ years undergoing elective right-sided resection for $C D$ versus $C C$. Independent risk factors for surgical complications were identified through multivariable logistic regression for both groups. In a second step, surgical and medical 30-day morbidity was compared after risk adjustment. Results: The cohort consisted of 17,516 patients, of which 2,899 (16.6\%) underwent surgery for $C D$ versus 14,617 (83.4\%) for CC. Independent risk factors for surgical complications in patients with $C D$ were male gender, African American race, ASA score (III or IV), active smoking, prolonged surgery, and preoperative anemia. Independent risk factors for surgical complications in the cancer group were age $\geq 70$ years, male gender, ASA score (III or
\end{abstract}

karger@karger.com www.karger.com/dsu

Karger ${ }^{\prime \prime} \div$

BOPEN ACCESS
(C) 2021 The Author(s)

Published by S. Karger AG, Basel

This is an Open Access article licensed under the Creative Commons Attribution-NonCommercial-4.0 International License (CC BY-NC) (http://www.karger.com/Services/OpenAccessLicense), applicable to the online version of the article only. Usage and distribution for commercial purposes requires written permission.
IV), respiratory and cardiovascular comorbidities, and preoperative hypoalbuminemia $(<3.5 \mathrm{~g} / \mathrm{dL})$. After risk adjustment, surgical complications (OR 1.25, $p=0.002$ ), sepsis (OR $1.64, p=0.012$ ), and unplanned readmissions (OR 1.39, $p=$ 0.004 ) were more common in patients with CD. Thirty-day mortality was higher in cancer patients ( 1.1 vs. $0.1 \%, p<$ 0.0001). Conclusions: Patients with Crohn's disease were more prone to surgical complications and postoperative sepsis compared to the cancer group undergoing the same procedure. Careful evaluation and correction of diseasespecific modifiable risk factors of patients with $C D$ and CC, respectively, are important.

(C) 2021 The Author(s)

Published by S. Karger AG, Basel

\section{Introduction}

Crohn's disease $(\mathrm{CD})$ is a challenging condition related to the chronicity of the disease in typically heavily pretreated and deconditioned patients with complicated or medically refractory disease [1]. As a result, there is often no true elective setting for CD surgery [2]. Widespread colon cancer (CC) screening, on the other hand, has led to an increasing number of primary elective segmental 
colectomies, which has become one of the most commonly performed procedures nationwide [3].

Several studies have implicated that CD diagnosis portends worse outcomes after right-sided resection when compared to those with a diagnosis of right-sided CC [46]. Given the heterogeneity of baseline characteristics of both patient populations, comparing surgical outcomes requires adjustment for disease-specific risk factors. Identification of these risk factors for both $\mathrm{CD}$ and CC surgery is important for tailoring of surgical management and appropriate decision-making process, as well as adequate counseling that ultimately translates into proper patient care $[7,8]$. The goal of this study was to compare disease-specific risk factors and 30-day outcomes between patients with $\mathrm{CD}$ and $\mathrm{CC}$ undergoing right-sided surgical resection.

\section{Methods}

\section{Data Source}

Data were accessed from the American College of SurgeonsNational Surgical Quality Improvement Program (ACS-NSQIP) Public Use File (PUF) January 2012 to December 2017. ACSNSQIP is an established, externally validated clinical database that was created for quality improvement purposes [9]. Demographic, anthropometric, perioperative, and postoperative data from the participant sites are collected by trained abstractors using standardized definitions.

\section{Cohort Selection}

All adult ( $\geq 18$ years) patients undergoing elective right colectomy and index ileocecal resection for CC and CD, respectively, were included using the International Classification of Diseases (ICD 9) 153.x for CC and 555.x for CD or (ICD10) C18.x for CC and K50.xx for CD and Current Procedure Terminology (CPT) codes $(44,160$ for open partial colectomy with terminal ileum resection with ileocolostomy and 44,205 for laparoscopic partial colectomy with terminal ileum resection with ileocolostomy). Patients with diverting ileostomy were not retained.

According to ACS-NSQIP, elective surgery was defined as surgery for patients in whom the operation was not reported by the surgeon as an emergent and the patient presented from home for a prescheduled surgery. Patients undergoing urgent or emergent surgery, suffering from preoperative septic shock, graded American Society of Anesthesiologists (ASA) class V, or undergoing a concurrent operation under the responsibility of a different primary surgeon were excluded.

Baseline demographics, comorbidities, laboratory parameters (albumin, hematocrit, and platelet count), and surgical details (approach and operating time) were compared between the 2 groups (CD vs. CC). Specific risk factors for surgical complications including chronic steroid use (regular administration of corticosteroid medications or immunosuppressant medications for a chronic medical condition within the 30 days before the primary procedure), anemia, severe malnutrition (preoperative weight loss $\geq 10 \% / 6$ preoperative months and body mass index [BMI] $<18.5 \mathrm{~kg} / \mathrm{m}^{2}$ ), functional status, ASA class, cardiovascular/respiratory comorbidities, and diabetes mellitus were assessed and compared between the 2 groups through uni- and multivariate analysis. Study outcomes of interest were postoperative 30-day complications according to standardized ACS-NSQIP definitions, which were regrouped as surgical (including surgical site infection, wound disruption, systemic sepsis [regrouping both septic shock and/or sepsis], postoperative ileus, unplanned reoperation, and need for blood transfusion) and medical (including urinary tract infection, respiratory complications [unplanned intubation, pneumonia, and failure to wean from mechanical ventilation], renal complications [acute kidney injury and progressive renal insufficiency], cardiac complications [pulmonary embolism, cardiac arrest, and myocardial infarction], and vascular thromboembolism). Unplanned readmission, unplanned reoperation, index length of stay (LOS), and 30-day mortality were also assessed.

\section{Statistical Analysis}

Descriptive statistics are reported as percentages for categorical variables and as median (interquartile range) for continuous variables. The differences between the variables were examined using the $\chi^{2}$ test for categorical variables or the Wilcoxon rank-sum test for continuous variables. Outcomes with an $\alpha$ level of $<0.1$ after univariable analysis were included in the multivariable models to compute adjusted odds ratios (OR). Multivariable binary logistic regression was used to identify risk factors for overall complications in patients with $\mathrm{CD}$ and patients with $\mathrm{CC}$ and to study the association between $\mathrm{CD}$ and $\mathrm{CC}$ and postoperative outcomes. For this study, an a level of $<0.05$ was considered statistically significant. Data analysis was performed using Statistical Package for the Social Sciences (SPSS) Advanced Statistics 25 (IBM Software Group, Inc., Armonk, NY, USA).

\section{Results}

In total, 17,516 patients were included; 2,899 (16.6\%) had ileocolonic CD versus 14,617 (83.4\%) with right-sided CC. Preoperative baseline demographics, comorbidities, and laboratory values of both groups are detailed in Table 1. Patients with CD were significantly younger with a higher preponderance of (severe) malnutrition, recent weight loss $\geq 10 \%$, and chronic steroid use. Cancer patients suffered from more comorbidities, including diabetes mellitus, cardiovascular, renal, and respiratory conditions with associated higher ASA score. While minimally invasive approach was used in both groups, they were less commonly performed in patients with CD. Furthermore, length of operation was longer in the $\mathrm{CD}$ group.

\section{Postoperative Outcomes}

Patients with CD were more prone to sepsis and readmissions. Cancer patients suffered more medical compli- 
Table 1. Demographic, preoperative, and surgical data

$\begin{array}{llll}\text { CD, } & \text { CC, } & \text { Overall, } & p \text { value } \\ n=2,899 & n=14,617 & N=17,516 & \\ & & \end{array}$

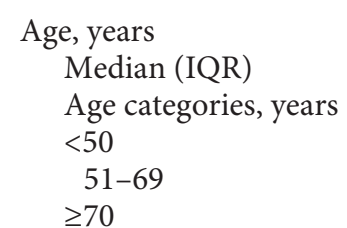

Gender, male

Race

White

African American

Asian

Others

Unknown/not reported

BMI, $\mathrm{kg} / \mathrm{m}^{2}$

Median (IQR)

Normal

Underweight

Overweight

Obese

Missing

ASA class (III or IV)

Diabetes mellitus

Current smoker

History of severe COPD

Functional health status

Independent

Dependent

Missing

CHF within 30 days of surgery

Hypertension requiring medication

Hemodialysis

Chronic steroid use

Preoperative loss of body weight; $\geq 10 \% / 6$ months

Severe malnutrition, loss of body weight $\geq 10 \% / 6$ months, and $\mathrm{BMI}<18.5 \mathrm{~kg} / \mathrm{m}^{2}$

PRBC transfusion within $72 \mathrm{~h}$ of surgery

Minimally invasive surgery

Operation time, min, median (IQR)

Preoperative albumin

Median (IQR)

$<3.5 \mathrm{~g} / \mathrm{dL}$

Missing

Preoperative hematocrit

Median (IQR)

$<35 \%$

Missing

Preoperative platelet count

Median (IQR)

$<150,000 / \mathrm{mL}$

Missing

$38(29-52)$
$2,061(71.1 \%)$
$724(25.0 \%)$
$114(3.9 \%)$
$1,276(44.0 \%)$
$2,381(82.1 \%)$
$256(8.8 \%)$
$19(0.7 \%)$
$8(0.3 \%)$
$235(8.1 \%)$

$\begin{aligned} 25 & (22-29) \\ 1,266 & (43.7 \%) \\ 203 & (7 \%) \\ 801 & (27.6 \%) \\ 622 & (21.5 \%) \\ 7 & (0.2 \%) \\ 913 & (31.5 \%) \\ 70 & (2.4 \%) \\ 635 & (21.9 \%) \\ 32 & (1.1 \%)\end{aligned}$

$2,886(99.6 \%)$

$7(0.2 \%)$

$6(0.2 \%)$

$3(0.1 \%)$

$449(15.5 \%)$

$4(0.1 \%)$

$1,692(58.4 \%)$

$169(5.8 \%)$

$$
\begin{array}{r}
40(1.4 \%) \\
6(0.2 \%)
\end{array}
$$

$1,739(60.0 \%)$

141 (106-185)

$3.9(3.5-4.2)$

$592(20.4 \%)$

839 (28.9\%)

$$
\begin{aligned}
& 39(35.4-42) \\
& 615(21.2 \%) \\
& 185(6.4 \%)
\end{aligned}
$$

$293(237-368)$
$61(2.1 \%)$
$215(7.4 \%)$

$\begin{array}{cr}71(62-79) & 68(56-77) \\ 778(5.3 \%) & 2,839(16.2 \%) \\ 5,894(40.3 \%) & 6,618(37.8 \%) \\ 7,945(54.4 \%) & 8,059(46.0 \%) \\ 6,885(47.1 \%) & 8,161(46.6 \%)\end{array}$

$10,419(71.3 \%)$

$1,401(9.6 \%)$

$398(2.7 \%)$

$56(0.4 \%)$

$2,343(16.0 \%)$

$28(24-28)$

$4,102(28.1 \%)$

$287(2 \%)$

4,913 (33.6\%)

$5,244(35.9 \%)$

$71(0.5 \%)$

$9,353(64 \%)$

3,062 (20.9\%)

$1,671(11.4 \%)$

$955(6.5 \%)$

$14,193(97.1 \%)$

$337(2.3 \%)$

$87(0.6 \%)$

$131(0.9 \%)$

$8,763(60.0 \%)$

$70(0.5 \%)$

$503(3.4 \%)$

$570(3.9 \%)$

$$
50(0.3 \%)
$$

$191(1.3 \%)$

$10,267(70.2 \%)$

$130(97-172)$

$3.9(3.5-4.2)$

$2,621(17.9 \%)$

$4,186(28.6 \%)$
$25.9(31.9-40)$
$6,175(42.2 \%)$
$441(3 \%)$
265 (213-334)
$731(5 \%)$
$571(3.9 \%)$

$<0.0001$

$<0.0001$

0.002

$12,800(73.1 \%)$

1,657 (9.5\%)

$417(2.4 \%)$

$64(0.4 \%)$

$2,578(14.7 \%)$

$27(24-32)$

$5,368(30.6 \%)$

$490(2.8 \%)$

$5,714(32.6 \%)$

$5,866(33.5 \%)$

$78(0.4 \%)$

$10,266(58.6 \%)$

$3,132(17.9 \%)$

2,306 (13.2\%)

$987(5.6 \%)$

$<0.0001$

$17,079(97.5 \%)$

$344(2.0 \%)$

$93(0.5 \%)$

$134(0.8 \%)$

$9,212(52.6 \%)$

$74(0.4 \%)$

$2,195(12.5 \%)$

739 (4.2\%)

$<0.0001$

$<0.0001$

$<0.0001$

$<0.0001$

$<0.0001$

$<0.0001$

$<0.0001$

0.01

$<0.0001$

$<0.0001$

$90(0.5 \%)$

$197(1.1 \%)$

$12,006(68.5 \%)$

$132(98-174)$

$<0.0001$

$<0.0001$

$<0.0001$

$<0.0001$

$$
\begin{array}{cc}
3.9(3.5-4.2) & 0.2 \\
3,213(18.3 \%) & \mathbf{0 . 0 0 3}
\end{array}
$$

$5,025(28.7 \%)$

$37(32.6-41)$
$6,790(38.8 \%)$
$626(3.6 \%)$

$268(216-336)$
$792(4.5 \%)$
$786(4.5 \%)$

$<0.0001$

$<0.0001$

$<0.0001$

$<0.0001$

$\mathrm{CD}$, Crohn's disease; CC, colon cancer; BMI, body mass index; DM, diabetes mellitus; COPD, chronic obstructive pulmonary disease; CHF, congestive heart failure; PRBC, packed red blood cells; ASA, American Society of Anesthesiologists; IQR, interquartile range. Figures in bold indicate statistical significance. 
Table 2. Postoperative complications

\begin{tabular}{|c|c|c|c|c|c|}
\hline & $\begin{array}{l}\mathrm{CD}, \\
n=2,899\end{array}$ & $\begin{array}{l}\text { CC, } \\
n=14,617\end{array}$ & $\begin{array}{l}\text { Overall, } \\
N=17,516\end{array}$ & $p$ value & Adjusted OR $(95 \% \mathrm{CI})^{\mathrm{a}}$ \\
\hline Surgical complications ${ }^{\mathrm{b}}$ & $1,094(37.7 \%)$ & $5,773(39.5 \%)$ & $6,867(39.2 \%)$ & 0.077 & $1.250(1.088-1.435), p$ value 0.002 \\
\hline Any SSI & $282(9.7 \%)$ & $1,036(7.1 \%)$ & $1,318(7.5 \%)$ & $<0.0001$ & $1.181(0.943-1.480), p$ value 0.148 \\
\hline Superficial incisional & $124(4.3 \%)$ & $552(3.8 \%)$ & $676(3.9 \%)$ & 0.2 & na \\
\hline Deep incisional & $20(0.7 \%)$ & $82(0.6 \%)$ & $102(0.6 \%)$ & 0.4 & na \\
\hline Organ/space & $154(5.3 \%)$ & $431(2.9 \%)$ & $585(3.3 \%)$ & $<0.0001$ & $1.318(0.960-1.809), p$ value 0.088 \\
\hline Wound disruption & $15(0.5 \%)$ & $91(0.6 \%)$ & $106(0.6 \%)$ & 0.5 & na \\
\hline Systemic sepsis & $112(3.9 \%)$ & $434(3 \%)$ & $546(3.1 \%)$ & 0.011 & $1.237(0.875-1.750), p$ value 0.229 \\
\hline Sepsis & $101(3.5 \%)$ & $271(1.9 \%)$ & $372(2.1 \%)$ & $<0.0001$ & $1.640(1.114-2.413), p$ value 0.012 \\
\hline Septic shock & $12(0.4 \%)$ & $165(1.1 \%)$ & $177(1 \%)$ & 0.001 & $0.419(0.186-0.946), p$ value 0.036 \\
\hline \multicolumn{6}{|l|}{ Ileus } \\
\hline Yes & $224(7.7 \%)$ & $1,185(8.1 \%)$ & $1,409(8 \%)$ & $<0.0001$ & $1.010(0.791-1.289), p$ value 0.947 \\
\hline Missing & $844(29.1 \%)$ & $5,054(34.6 \%)$ & $5,898(33.7 \%)$ & & $0.903(0.785-1.039), p$ value 0.155 \\
\hline \multicolumn{6}{|r|}{ 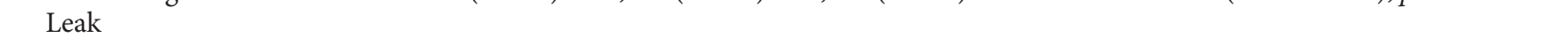 } \\
\hline Yes & $81(2.8 \%)$ & $229(1.6 \%)$ & $310(1.8 \%)$ & $<0.0001$ & $1.089(0.701-1.692), p$ value 0.704 \\
\hline Missing & $844(29.1 \%)$ & $5,062(34.6 \%)$ & $5,906(33.7 \%)$ & & $0.899(0.784-1.032), p$ value 0.131 \\
\hline Unplanned reoperation & $110(3.8 \%)$ & $527(3.6 \%)$ & $637(3.6 \%)$ & 0.6 & \\
\hline Need for blood transfusion & $125(4.3 \%)$ & $1,388(9.5 \%)$ & $1,513(8.6 \%)$ & $<0.0001$ & $0.649(0.488-0.863), p$ value 0.003 \\
\hline Medical complications ${ }^{\mathrm{c}}$ & $104(3.6 \%)$ & $1,022(7 \%)$ & $1,126(6.4 \%)$ & $<0.0001$ & $0.806(0.594-1.094), p$ value 0.167 \\
\hline UTI & $31(1.1 \%)$ & $237(1.6 \%)$ & $268(1.5 \%)$ & 0.03 & $0.970(0.544-1.731), p$ value 0.918 \\
\hline Respiratory complication $^{\mathrm{d}}$ & $34(1.2 \%)$ & $454(3.1 \%)$ & $488(2.8 \%)$ & $<0.0001$ & $0.747(0.456-1.224), p$ value 0.247 \\
\hline Renal complications $\mathrm{s}^{\mathrm{e}}$ & $12(0.4 \%)$ & $124(0.8 \%)$ & $136(0.8 \%)$ & 0.015 & $1.647(0.738-3.674), p$ value 0.223 \\
\hline Cardiac complications $\mathrm{s}^{\mathrm{f}}$ & $6(0.2 \%)$ & $176(1.2 \%)$ & $182(1 \%)$ & $<0.0001$ & $0.614(0.239-1.579), p$ value 0.312 \\
\hline VTE $^{\mathrm{g}}$ & $31(1.1 \%)$ & $244(1.7 \%)$ & $275(1.6 \%)$ & 0.018 & $0.616(0.350-1.084), p$ value 0.093 \\
\hline LOS, median (IQR), days & $4(3-8)$ & $4(3-9)$ & $4(3-9)$ & 0.015 & \\
\hline $\mathrm{LOS}>5$ days $(\mathrm{Q} 3)$ & $871(30 \%)$ & $4,447(30.4 \%)$ & $5,318(30.4 \%)$ & 0.7 & na \\
\hline Unplanned readmission & $285(9.8 \%)$ & $1,059(7.2 \%)$ & $1,344(7.7 \%)$ & $<0.0001$ & $1.393(1.110-1.749), p$ value 0.004 \\
\hline Mortality (within 30 days) & $3(0.1 \%)$ & $163(1.1 \%)$ & $166(0.9 \%)$ & $<0.0001$ & $0.186(0.048-0.723), p$ value 0.015 \\
\hline
\end{tabular}

CD, Crohn's disease; CC, colon cancer; VTE, vascular thromboembolism; SSI, surgical site infection; LOS, length of stay; UTI, urinary tract infection; COPD, chronic obstructive pulmonary disease; CHF, congestive heart failure. Figures in bold indicate statistical significance. ${ }^{a} \mathrm{CC}$ was used as a reference. Adjusted for age, gender, race, BMI, operative approach, diabetes mellitus, current smoker within 1 year, history of severe COPD, functional health status prior to surgery, CHF in 30 days before surgery, hypertension requiring medication, currently on dialysis (pre-op), steroid use for chronic condition, $>10 \%$ loss body weight in last 6 months, transfusion $\geq 1$ units in $72 \mathrm{~h}$ before surgery, ASA classification, total operation time, albumin $<3.5 \mathrm{~g} / \mathrm{dL}$, hematocrit $<35 \%$, and platelets $<150 \mathrm{k} / \mathrm{mL}$. b Surgical complications include SSI, wound disruption, systemic sepsis, postoperative ileus, leak, unplanned reoperation, need for blood transfusion, and/or LOS $>5$ days. ${ }^{c}$ Medical complications include UTI, respiratory complications, renal complications, cardiac complications, and/or VTE. ${ }^{\mathrm{d}}$ Respiratory complications include pneumonia, unplanned intubation, and/or on ventilator $\geq 48 \mathrm{~h}$. ${ }^{\mathrm{e}}$ Renal complications include progressive renal insufficiency and/or acute kidney injury. ${ }^{\mathrm{f}}$ Cardiac complications include cardiac arrest requiring cardiopulmonary resuscitation and/or myocardial infarction. ${ }^{\mathrm{g}}$ VTE includes deep venous thrombosis and/or pulmonary embolism.

cations including respiratory, cardiovascular, and urinary complications (Table 2). Unplanned reoperation rates were comparable ( 3.8 vs. $3.6 \%, p=0.6$ ), while overall 30 -day mortality was higher in cancer patients (1.1 vs. $0.1 \%$ in CD, $p<0.001)$. Median LOS was similar in both groups: 4 (IQR 3-8) days for CD and 4 (IQR 3-9) days for cancer patients $(p=0.015)$.

After risk adjustment, surgical complications, sepsis, and unplanned readmissions were higher in patients with CD. Cancer patients were more prone to septic shock, need for blood transfusion, and unplanned intubation and had a higher 30-day mortality (Table 2).

\section{Disease-Specific Risk Factors}

Independent unmodifiable risk factors for surgical complications in patients with CD were male gender, African American race, and ASA score, while the independent modifiable risk factors were active smoking and preoperative anemia. Independent unmodifiable risk factors for surgical complications in the cancer group were age 


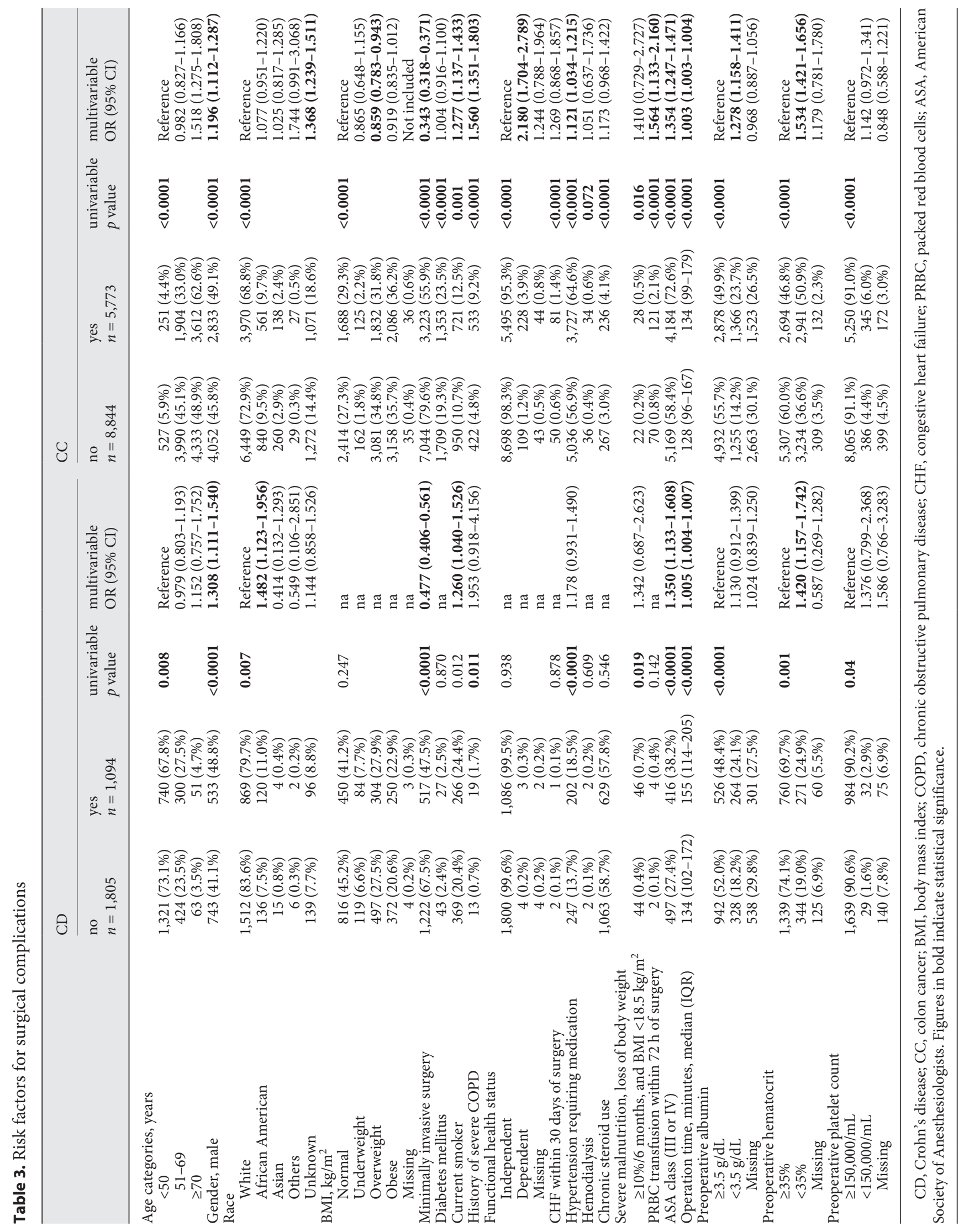


$\geq 70$ years, male gender, ASA score (III or IV), history of severe COPD, and dependent functional health status, while the independent modifiable risk factors were active smoking, hypertension requiring medication, blood transfusion within $72 \mathrm{~h}$ of surgery, and preoperative hypoalbuminemia $(<3.5 \mathrm{~g} / \mathrm{dL})$. Minimally invasive surgery was protective in both groups, while prolonged surgery was associated with an increased risk of surgical complications (Table 3).

\section{Discussion}

The present study highlights important differences in patient characteristics and risk factors of $\mathrm{CD}$ and cancer patients undergoing right-sided elective surgery. Surgical and infectious complications were higher in the $\mathrm{CD}$ group as well as after risk adjustment for the baseline confounders. On the other hand, the cancer group experienced more medical complications and higher 30-day mortality. While smoking, high comorbidity index, open surgery, and male gender were identified as risk factors for surgical complications in both conditions, this study emphasizes the importance of proper conditioning of patients with CD by addressing preoperative anemia. Respiratory/cardiovascular comorbidities and functional dependence combined with malnutrition were identified as major predictors of adverse outcomes in the older cancer cohort. Correcting the modifiable deficits, when feasible, likely contributes to better short-term surgical outcomes.

Right colectomy for cancer is a standardized procedure carried out by most general surgeons [10]. Because of the preponderance of terminal ileal disease and a 10year risk of surgical resection of almost 50\%, many patients with $\mathrm{CD}$ eventually require ileocolonic resections $[11,12]$. Because of the complexity of medical management requiring thorough surveillance and follow-up, patients with $\mathrm{CD}$ are treated in dedicated inflammatory bowel disease units [13]. ACS-NSQIP does not discriminate between specific settings or case volume of contributing centers and disposes of a limited amount of diseasespecific variables. However, the dataset yields a $20 \%$ representative sample of the US surgical population [14]. Thus, considering the large scale of this study, a risk-adjusted comparative analysis may help to better understand disease-specific risk factors and outcomes when comparing right-sided colon resections in both conditions.

Overall, postoperative morbidity compared well to previous reports from other large data registries for both disease categories [15-17]. However, national data analyses bear a risk of skewing outcomes due to underreporting and missing data, which needs to be strongly considered for this present comparative analysis [18]. With $5.3 \%$, the rate of clinically relevant organ-space infections in the CD group was significantly higher than in the cancer cohort (2.9\%). This may, together with the increased rate of postoperative sepsis in patients with $\mathrm{CD}$, reflect both immunosuppression and complicated disease states. This finding is in line with previous literature describing an increased risk of $\mathrm{CD}$-associated postoperative infectious complications, especially in the setting of hypoalbuminemia and steroid use $[19,20]$. Collectively, this highlights the importance of the surgical decision-making process regarding restoration of gastrointestinal continuity at index surgery versus the creation of an ileostomy. Of note, the slightly higher rate of septic shock in the cancer group despite a lower occurrence of sepsis is likely related to age-related impaired physiologic tolerance of sepsis in this population [21]. The older cancer cohort, presenting with more age-related comorbidities, was prone to both medical complications and increased 30day mortality. Functional recovery (mobilization and alimentation) was likely accelerated in the younger CD population, which may have further contributed to decreased medical complications [12]. While LOS was similar in both groups ( $70 \%$ discharged within 5 days), (risk-adjusted) readmissions were higher in patients with $\mathrm{CD}$. The increased 30-day mortality in the significantly older cancer cohort represents an expected finding.

The main purpose of this study was to identify diseasespecific risk factors for $\mathrm{CD}$ and cancer to identify potentially modifiable risk factors. The findings support the importance of preoperative optimization of patients with $\mathrm{CD}$ including smoking cessation, correction of anemia, nutritional deficiencies, and electrolyte abnormalities in the elective setting $[22,23]$. This is even more important in the light of prevailing deep infections and septic complications after CD surgery, confirming the beneficial impact of preoperative optimization [24-26]. Our analysis further suggests that prehabilitation strategies may be beneficial in cancer patients with particular focus on smoking cessation and respiratory conditioning to mitigate risks related to general anesthesia and to promote postoperative recovery [27]. Furthermore, best possible control of cardiovascular risk factors such as hypertension and anemia may help to further improve surgical outcomes $[28,29]$. Of note, the higher incidence of surgical complications in African American patients has been previously observed and may be related to differences in 
socioeconomic status, access to health care, and thus an increased risk of complicated disease presentations in these patients [30].

It is important to mention that preoperative optimization can be challenging in both patients with $\mathrm{CD}$ and patients with CC. Patients with CD are usually chronically immune suppressed, and the main surgical indication is typically medically refractory, complicated disease. Hence, delaying surgery to account for preoperative risk factors may be associated with disease progression and worse outcomes [31]. On the other side, patients with CC are usually older and present with multiple comorbidities, and significantly delaying surgical resection of primary cancer may be associated with worse survival outcomes [32, 33].

This study has limitations beyond its retrospective design and limitations related to ACS-NSQIP in general. Details about both previous and preoperative CD management are lacking and impede further analysis of safety profiles beyond chronic steroid use as a surrogate for disease severity. This represents a significant limitation given the potential impact according to type, number, timing, and duration of previous or ongoing medical CD therapy on postoperative short-term outcomes. The data pool is heterogeneous, and specifics on perioperative care, caseload, and institutional settings are lacking. The ACS-NSQIP ${ }^{\circledR}$ definition for elective surgery (coming from home) may not be entirely representative of actual disease severity in patients with CD, despite independent preoperative functional health status in most patients. The large, representative dataset and the focus on a single, frequently performed procedure may help to alleviate some of these shortcomings.

\section{Conclusions}

Patients with CD were more prone to surgical complications and postoperative sepsis compared to the cancer group undergoing right-sided resections. Careful evaluation and correction of disease-specific modifiable risk factors of both $\mathrm{CD}$ and cancer patients when possible are important to reduce postoperative morbidity.

\section{Statement of Ethics}

No ethical approval was needed as this study utilized a national database with no attempt to identify the patients.

\section{Conflict of Interest Statement}

There are no conflicts of interest to declare.

\section{Funding Sources}

This research did not receive any specific grant from funding agencies in the public, commercial, or nonprofit sectors.

\section{Author Contributions}

F.G., M.A.A., W.P., K.T.B., S.S., K.L.M., and D.W.L: conception and design, analysis and interpretation of data, and drafting of the manuscript. M.A.A. and F.G.: acquisition of data. All authors were involved in critical revision of the manuscript and final approval of the version to be published.

\section{References}

1 Ng SC, Shi HY, Hamidi N, Underwood FE, Tang W, Benchimol EI, et al. Worldwide incidence and prevalence of inflammatory bowel disease in the 21st century: a systematic review of population-based studies. Lancet. 2018;390(10114):2769-78.

2 Wasmann KA. IBD study group Amsterdam UMC, location AMC: complications while waiting for IBD surgery-short report. J Crohns Colitis. 2020;14(2):277-80.

3 Lee MG, Chiu CC, Wang CC, Chang CN, Lee $\mathrm{SH}$, Lee $\mathrm{M}$, et al. Trends and outcomes of surgical treatment for colorectal cancer between 2004 and 2012: an analysis using National Inpatient Database. Sci Rep. 2017;7(1):2006.

4 Iesalnieks I, Spinelli A, Frasson M, Di Candido F, Scheef B, Horesh N, et al. Risk of postoperative morbidity in patients having bowel resection for colonic Crohn's disease. Tech Coloproctol. 2018;22(12):947-53.

5 Hossne RS, Sassaki LY, Baima JP, Meira Júnior JD, Campos LM. Analysis of risk factors and postoperative complications in patients with Crohn's disease. Arq Gastroenterol. 2018 Jul-Sep;55(3):252-7.

6 Shental O, Tulchinsky H, Greenberg R, Klausner JM, Avital S. Positive histological inflammatory margins are associated with increased risk for intra-abdominal septic complications in patients undergoing ileocolic resection for Crohn's disease. Dis Colon Rectum. 2012; 55(11):1125-30.

7 Nickerson TP, Merchea A. Perioperative considerations in Crohn disease and ulcerative colitis. Clin Colon Rectal Surg. 2016;29(2): $80-4$.
8 Alós R, Hinojosa J. Timing of surgery in Crohn's disease: a key issue in the management. World J Gastroenterol. 2008;14(36):5532-9.

9 First results of the Swiss national surgical site infection surveillance program: who seeks shall find: ERRATUM. Infect Control Hosp Epidemiol. 2017;38(11):1389.

10 Lotti M, Capponi MG, Campanati L, Bertoli P, Palamara F, Coccolini F, et al. Laparoscopic right colectomy: miles away or just around the corner? J Minim Access Surg. 2016;12(1):41-6.

11 Langholz E. Current trends in inflammatory bowel disease: the natural history. Therap Adv Gastroenterol. 2010;3(2):77-86.

12 Grass F, Lovely JK, Crippa J, Ansell J, Hübner $\mathrm{M}$, Mathis KL, et al. Comparison of recovery and outcome after left and right colectomy. Colorectal Dis. 2019;21(4):481-6. 
13 Strohl M, Gonczi L, Kurt Z, Bessissow T, Lakatos PL. Quality of care in inflammatory bowel diseases: what is the best way to better outcomes? World J Gastroenterol. 2018; 24(22):2363-72.

14 Eisenstein S, Holubar SD, Hilbert N, Bordeianou L, Crawford LA, Hall B, et al. The ACS national surgical quality improvement program-inflammatory bowel disease collaborative: design, implementation, and validation of a disease-specific module. Inflamm Bowel Dis. 2019;25(11):1731-9.

15 Abdalla S, Brouquet A, Maggiori L, Zerbib P, Denost Q, Germain A, et al. Postoperative morbidity after iterative ileocolonic resection for Crohn's disease: should we be worried? A prospective multicentric cohort study of the GETAID Chirurgie. J Crohns Colitis. 2019; 13(12):1510-7.

16 Yamamoto T, Spinelli A, Suzuki Y, SaadHossne R, Teixeira FV, de Albuquerque IC, et al. Risk factors for complications after ileocolonic resection for Crohn's disease with a major focus on the impact of preoperative immunosuppressive and biologic therapy: a retrospective international multicentre study. United European Gastroenterol J. 2016;4(6) 784-93.

17 Ju T, Haskins IN, Kuang X, Amdur RL, Brody FJ, Obias V, et al. Robotic right colectomy for colon cancer: comparison of outcomes from a single institution with the ACS-NSQIP database. J Laparoendosc Adv Surg Tech A. 2019;29(1):40-4.

18 Gibbons CL, Mangen MJ, Plass D, Havelaar $\mathrm{AH}$, Brooke RJ, Kramarz P, et al. Measuring underreporting and under-ascertainment in infectious disease datasets: a comparison of methods. BMC Public Health. 2014;14:147.
19 Nguyen GC, Elnahas A, Jackson TD. The impact of preoperative steroid use on short-term outcomes following surgery for inflammatory bowel disease. J Crohns Colitis. 2014;8(12): 1661-7.

20 Nguyen GC, Du L, Chong RY, Jackson TD. Hypoalbuminaemia and postoperative outcomes in inflammatory bowel disease: the NSQIP surgical cohort. J Crohns Colitis. 2019;13(11):1433-8.

21 Inoue S, Suzuki K, Komori Y, Morishita Y, Suzuki-Utsunomiya K, Hozumi K, et al. Persistent inflammation and $\mathrm{T}$ cell exhaustion in severe sepsis in the elderly. Crit Care. 2014; 18(3):R130.

22 Grass F, Pache B, Martin D, Hahnloser D, Demartines N, Hübner M. Preoperative nutritional conditioning of Crohn's patientssystematic review of current evidence and practice. Nutrients. 2017;9(6):562.

23 Forbes A, Escher J, Hébuterne X, Kłęk S, Krznaric Z, Schneider S, et al. ESPEN guideline: clinical nutrition in inflammatory bowel disease. Clin Nutr. 2017;36(2):321-47.

24 Bellolio F, Cohen Z, Macrae HM, O’Connor BI, Huang H, Victor JC, et al. Outcomes following surgery for perforating Crohn's disease. Br J Surg. 2013;100(10):1344-8.

25 Crowell KT, Messaris E. Risk factors and implications of anastomotic complications after surgery for Crohn's disease. World J Gastrointest Surg. 2015;7(10):237-42.

26 Sharma A, Chinn BT. Preoperative optimization of Crohn disease. Clin Colon Rectal Surg. 2013;26(2):75-9.
27 Bruns ER, van den Heuvel B, Buskens CJ, van Duijvendijk P, Festen S, Wassenaar EB, et al. The effects of physical prehabilitation in elderly patients undergoing colorectal surgery: a systematic review. Colorectal Dis. 2016; 18(8):O267-77.

28 Scheede-Bergdahl C, Minnella EM, Carli F. Multi-modal prehabilitation: addressing the why, when, what, how, who and where next? Anaesthesia. 2019;74(Suppl 1):20-6.

29 Gillis C, Buhler K, Bresee L, Carli F, Gramlich L, Culos-Reed N, et al. Effects of nutritional prehabilitation, with and without exercise, on outcomes of patients who undergo colorectal surgery: a systematic review and meta-analysis. Gastroenterology. 2018;155(2):391-e4.

30 Arsoniadis EG, Ho YY, Melton GB, Madoff RD, Le C, Kwaan MR. African Americans and short-term outcomes after surgery for Crohn's disease: an ACS-NSQIP analysis. J Crohns Colitis. 2017;11(4):468-73.

31 Leeds IL, Sundel MH, Gabre-Kidan A, Safar B, Truta B, Efron JE, et al. Outcomes for ulcerative colitis with delayed emergency colectomy are worse when controlling for preoperative risk factors. Dis Colon Rectum. 2019; 62(5):600-7.

32 Larson DW, Abd El Aziz MA, Mandrekar JN. How many lives will delay of colon cancer surgery cost during the COVID-19 pandemic? an analysis based on the US national cancer database. Mayo Clin Proc. 2020;95(8): $1805-7$.

33 Grass F, Behm KT, Duchalais E, Crippa J, Spears GM, Harmsen WS, et al. Impact of delay to surgery on survival in stage I-III colon cancer. Eur J Surg Oncol. 2020;46(3):455-61. 